\title{
Intelligence artificielle et machine à remonter le temps
}

\author{
Jean Martin
}

Dr méd., membre de la rédaction

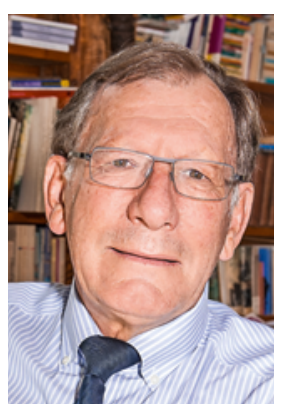

Stephen Hawking, le physicien de Cambridge, dans un interview à la $\mathrm{BBC}$ : «Le développement de l'intelligence artificielle (IA) pourrait provoquer la fin du genre humain. Les humains sont limités par une évolution biologique lente et ne pourraient concurrencer les machines qui se reprogramment rapidement.» Je n'ai aucune prétention à être dans la même ligue que Hawking, mais le fait est que cette disparité des vitesses d'adaptation me préoccupe vivement - comme elle préoccupe A. Geissbuhler, chef du service de cybersanté aux HUG de Genève [1]. Au plan mental (et même biologique), notre organisme est-il en mesure de s'adapter assez vite? Vous me direz que voir des enfants de trois ans pianoter sur des tablettes est rassurant à cet égard. Peut-être.

Par conviction ou idéologie, nous répugnons à croire que des machines seront plus intelligentes que l'homme. S. Garelli, professeur à l'Uni de Lausanne, rappelle toutefois que dès 1995 l'immensité des données à disposition a permis à des machines de mieux exploiter, avec leurs algorithmes, la richesse des informations [2]. Rappelant que, en 1997, Deeper Blue de IBM a battu aux échecs Garry Kasparov et que récemment un autre ordinateur a battu un grand champion du jeu de go. L'atout de l'IA est de se reprogrammer en puisant dans Big Data.

Question à dix mille (milliards?) de dollars: l'IA égalerat-elle - dépassera-t-elle - un jour Baudelaire écrivant de la poésie, ou Descartes ou Kant philosophant? J'ai l'impression que de plus en plus de gens sont prêts à supprimer la forme interrogative de cette phrase. Geissbuhler lui se dit «écartelé entre la certitude de la future suprématie de la machine et le souffle de l'homme [...] Retour à l'humain avec son don d'empathie, son intuition et ses doutes, devant lesquels les robots restent muets?»

A propos d'IA, à la Radio romande le 2 janvier 2017, question posée par un responsable syndical préoccupé: «Les robots paieront-ils des impôts pour financer la sécurité sociale?»

jean.martin[at]saez.ch
De son côté, F. Kaplan, professeur d'humanités digitales à l'EPFL, veut pour l'Europe la première Time Machine [3]. Le projet impressionne: proposer une infrastructure d'archivage et de calcul unique pour modéliser les données du passé, les réaligner sur le présent et se projeter vers l'avenir. Internet et al. se sont développés sans vraiment tenir compte de la dimen- sion temporelle, ils donnent à voir un 'grand maintenant'. Mais le présent numérique, documenté à la seconde près, est déjà l'archive de son futur... Ici, noter que Facebook, Google, s'ils existent encore dans 50 ans, seront les dépositaires de notre patrimoine irrémédiablement privatisé. Le voulons-nous?

La deuxième révolution d'Internet commence avec l'entrée en scène du temps comme principe d'indexation. Il ne s'agira plus d'archiver ponctuellement mais de dresser un pont entre l'ère de l'information globalisée et les époques précédentes. «Ce Big Data du passé documentera notre patrimoine culturel mais aussi notre héritage économique, scientifique et technique. [...] Cela permettra la construction de nouveaux modèles interprétatifs. Les épidémiologistes comprendront mieux la diffusion des grandes maladies, les économistes réinterpréteront l'histoire des croissances et crises du capitalisme, les linguistes comprendront le treillis évolutif de nos langues.» D’où, dit Kaplan, «le passé deviendra un territoire à habiter. L'IA permettra d'inférer la structure des espaces passés non-documentés, les trajectoires des acteurs de l'époque, en leur reconférant une dimension émotionnelle.»

Comme tous j'imagine, il m'est arrivé de rêver pouvoir vivre une journée au temps des Romains, des chevaliers, ou des Incas ou des Sioux avant la Conquista. Et bien on y est, à la mythique machine à remonter le temps, ou si près. Kaplan: «Nous serons demain les voyageurs du temps, le projet Time Machine est une occasion unique pour construire notre futur à partir d'un patrimoine commun.» Perspective que Churchill aurait appréciée, lui qui a dit «L'esprit humain est très inadéquat pour rendre justice à la complexité infinie des phénomènes», et "Plus vous saurez regarder loin dans le passé, plus vous verrez loin dans le futur». Il aurait cru au potentiel de l'IA. ${ }^{1}$

\section{Références}

1 Docteur 4.0 (rencontre avec le Dr Antoine Geissbuhler). Le Temps, 13 décembre 2016, p. 22.

2 Garelli Stéphane. Qui doit craindre l'intelligence artificielle? Le Temps (Lausanne), 10 décembre 2016, p. 16.

3 Kaplan Frédéric. L'Europe doit construire la première Time Machine. Le Temps, 15 décembre 2016, p. 10. 